\title{
Facilitating Students' Learning through M-LMS for Tablet Device
}

\author{
Mas Rina Mustaffa and Evi Indriasari Mansor
}

\begin{abstract}
Electronic learning management system (e-LMS) is widely used in the Higher-Education institutions to deliver and share learning contents among the students. However, most of the e-LMS are developed for offline or online desktops. The objective of the proposed mobile learning management system ( $m$-LMS) is to provide the flexibility of accessing and managing course materials at anywhere and anytime, making learning even more widely available. The m-LMS is equipped with many functions to allow for various related multimedia documents such as text, image, audio, and video to be uploaded, edited, deleted, tagged, and searched among the university students. Experimental results obtained from surveys have shown that the $\mathrm{m}$-LMS is able to provide better learning environment for the university learners, which lead to a deeper level of learning engagement.
\end{abstract}

Index Terms-Higher-education institutions, m-LMS, m-learning, multimedia documents.

\section{INTRODUCTION}

Electronic learning (e-learning) can be defined as the delivery of information and instructions to individuals with the utilization of computer and internet technologies to promote learning [1], [2]. The e-learning approach has foster changes on how individuals learn as opposed to the traditional education methods and provide many benefits such as increased accessibility to information, control over standardization content, learning sequence, and pace of learning, and personalized instruction [3], [4]. Although e-learning have so many advantages to offer, there are still some deficiencies of its own such as high cost for desktops, large area for desktop setting, and allowing access of learning materials only at a fixed location. Due to these reasons and with the advancement in technologies, mobile learning (m-learning) has been introduced.

M-learning refers to the utilization of mobile devices such as netbook, tablets, and smartphones in learning activities. With the large number of mobile devices and mobile users nowadays, the current learning trend is moving towards making the mobile devices as primary medium for communication and learning, especially in the universities [5], [6]. Mobile learning indeed has so many good things to

Manuscript received February 9, 2014; revised May 16, 2014. This work was supported by the Center of Academic Development (CADe), Universiti Putra Malaysia (UPM) under Research Incentive Grant in Teaching and Learning (GIPP) 9323630.

The authors are with the Multimedia Department, Faculty of Computer Science and Information Technology, Universiti Putra Malaysia, 43400 UPM Serdang, Selangor Darul Ehsan, Malaysia (e-mail: MasRina@upm.edu.my, Evi@upm.edu.my). offer to the learning community for the better of mankind such as promoting life-long learning, learning in the time of need, flexibility in terms of time and location, offer utilization of cheaper, smaller, and lighter weight mobile devices as opposed to desktops for e-learning [7], [8]. Mobile learning approach allows learning to be done on the go, for example when students are travelling or commuting. This means learners are able to have access to learning materials at their fingertips, anywhere and anytime, through mobile devices. Mobile technology also allow the learners to learn interactively while at the same time encourage them to take the initiative and direct their own learning activities. Students with physical disability also able to enjoy the same learning experience as the rest of the students through mobile learning since the learning materials can be accessed at home [9]. Hence, this learning approach needs to be further explored especially in facilitating the learning process.

Learning management system (LMS) is introduced as a platform for the educators and the learners to communicate in terms of educational materials and is widely adopted among universities globally [10]. It usually comprises of many tools that support various diverse functionalities such as accessing online readings and supplementary materials, working with peers and colleagues on tasks or assignments, generating and sharing multimedia materials, keeping up to date on the latest announcement and notifications, and many others [11]. With the emerging of computers and advancement in the internet technologies, LMS has been widely explored to support the traditional classroom teaching and learning. One of the existing e-LMS is the PutraLMS [12] where it enables the delivery, management, and administration of university-wide courses. The application however is not equipped with search function which makes it difficult for the students to manage related documents among the abundance of stored multimedia documents. E-Learning @UTM [13] is a LMS deployed using Moodle, which is an Open Source Course Management System, also a Virtual Learning Environment. The search function is available in the application, however students are unable to edit or revise any uploaded documents since there is no editor provided. CeL [14] is designed to enable teaching and learning through the use of TAR College internet technologies and has successfully supporting the teaching and learning process for the college since 1997. However, editor to edit documents are not available. Therefore, user has to upload the edited documents into the system as new documents. This may cause redundancy of documents if user did not delete the unwanted documents. Another major drawback of the existing e-LMS is that they mostly tend to focus on electronic learning with limited exploration on m-learning environment, specifically in utilizing tablet devices. Most of the previous works focuses 
on developing LMS for offline desktop programs or for internet applications running on desktops. Nowadays, it is a norm for student to own at least one tablet device. When implementing the LMS in m-learning environment, this can provide better learning opportunities for the students, lead to a deeper level of learning engagement, and allowing the students to understand the content better. Hence, further exploration on the capability of tablet devices in facilitating learning process through mobile-based LMS should be carried-out. Acknowledging the importance of mobile-based LMS, many researchers have explored the possibility of bringing the education to a greater level by designing and developing m-LMS. However, many of them self-proclaimed that the web-based LMS are actually mobile applications. This can be very misleading and inaccurate.

True mobile-based allows the applications to be connected to the user at all time, as long as there is an internet connectivity. Web-based applications do not have this luxury because the connection will only be established when the user is browsing the site. The key advantage of this is that it allows the application owners to share or forward any related information to the users at all time. Compared to web-based, mobile-based applications work with the device's built-in features, where they are easier to work with and also perform faster on the device. Mobile-based applications are also more interactive because the device is uniquely connected to the applications and can be distinguished at the application level. In general, web-based applications will not have this feature because the access is open to public and cannot be distinguished. Nevertheless, there are still efforts on true m-LMS which can be found in [15]-[17]. However, not many of the applications can be found for iOS platform although it has been claimed as one of the most popular and secured operating system [18]. Hence, this work aims to facilitate students' learning through m-LMS designed and developed for iPad.

\section{M-LMS DESIGN}

M-LMS is a personalized application for students' to manage their course materials anywhere and anytime, through a tablet device. The system is also user friendly and feature simple and easy navigation for students.

Fig. 1 shows the physical structure of the m-LMS while Fig. 2. shows the system's data flow diagram. The system is equipped with an authentication process for security purpose. When an authorized user enters the system, the main page will be shown. There are six navigational tab-bar buttons included such as Home, Course, Profile, About, Help, and Logout button. Home button brings user to view the related latest announcements. The Course button is for navigating to Courses List page where all courses which have been registered by the user will be displayed in a table. After user selects a course, Course Details page will be shown. All functions to manage documents such as Upload, Edit, Delete, and Search are available within this page. The system has four different editors to upload and edit the respective multimedia documents such as text, image, audio, and video.

Within each editor, students can edit their documents before uploading them using the functions provided in each editor. They can also view back and manage the uploaded document. For example, the students can revise or edit the uploaded documents using the editors provided and delete unwanted uploaded documents. Another additional feature is the tagging function that allows students to tag the documents before and after uploading them. This allows the students to search for related document using specific tags or title of the tagged documents. There are also the Course Information button and Student List button to display the related course information and list of students for that course. The profile button allows user to view and edit his/her profile. About button is for navigating to About page. Help button allows user to view general questions and details on the person in charge for the system. User can quit the system through the Logout button.

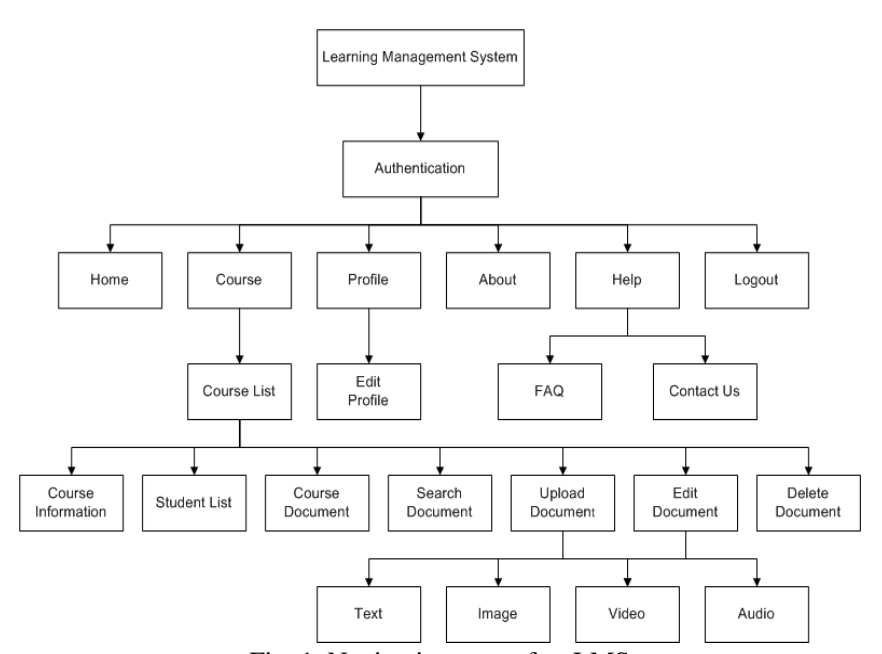

Fig. 1. Navigation map of m-LMS.

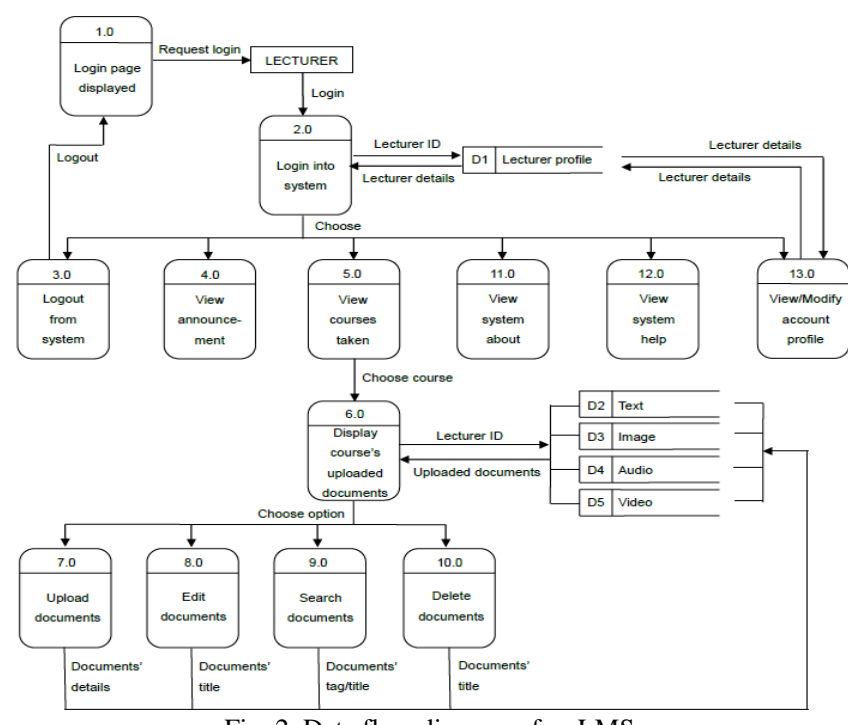

Fig. 2. Data flow diagram of m-LMS

\section{M-LMS PROTOTYPE}

The m-LMS is developed on iMac with OS X Mountain Lion 10.8.3, 2.7 GHz Intel Core i5, 8 GB 1600MHz DDR3. $\mathrm{m}$-LMS is specifically designed and developed for iPad device with iOS 6.0.1 above. The system is a native mobile application which can provide high performance and high degree of reliability. Objective- $\mathrm{C}$ is the main programming language used for development while the PHP is a server side scripting language that is used to connect to the database 
server. The development tools utilized are Xcode 4.5. TextWrangler is used as the text editor for writing the PHP to connect the application to database server. Adobe Photoshop is used for designing the interface for the m-LMS. All multimedia documents such as text, image, audio, and video is stored in XAMPP. XAMPP is used to connect the PHP with MySQL database server. PhpMyAdmin is used to handle the administration of MySQL with the use of web browser. m-LMS has a total of five database tables in MySQL. They are document table, images table, audio table, video table, and stuDetails table. Audio table is used to store the information of uploaded audio while document table is used to store the information of uploaded text. Image table and video table are used to store all information of uploaded image and video respectively. Next, all information related to the students are stored in the stuDetails database table.

Screenshots of the m-LMS prototype can be found in the following Fig. 3 - Fig. 7.

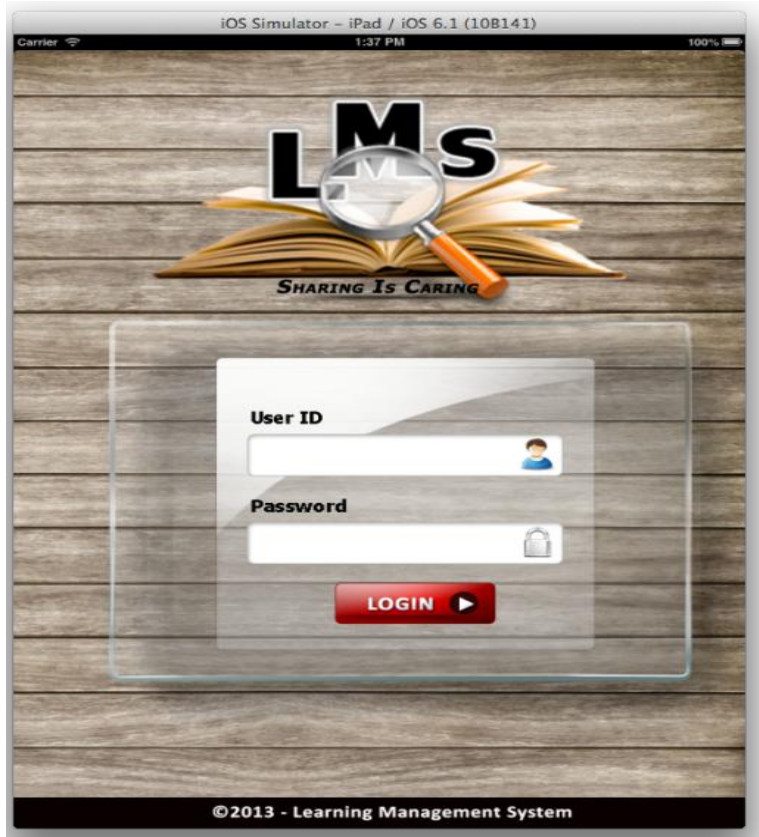

Fig. 3. Login page of m-LMS.

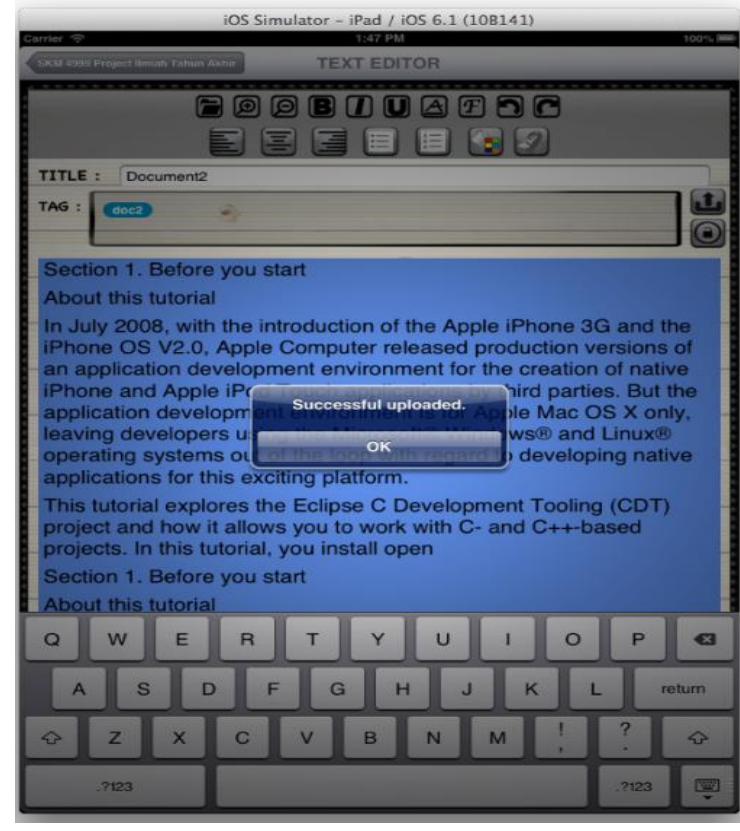

Fig. 4. Message of successful upload in text editor.

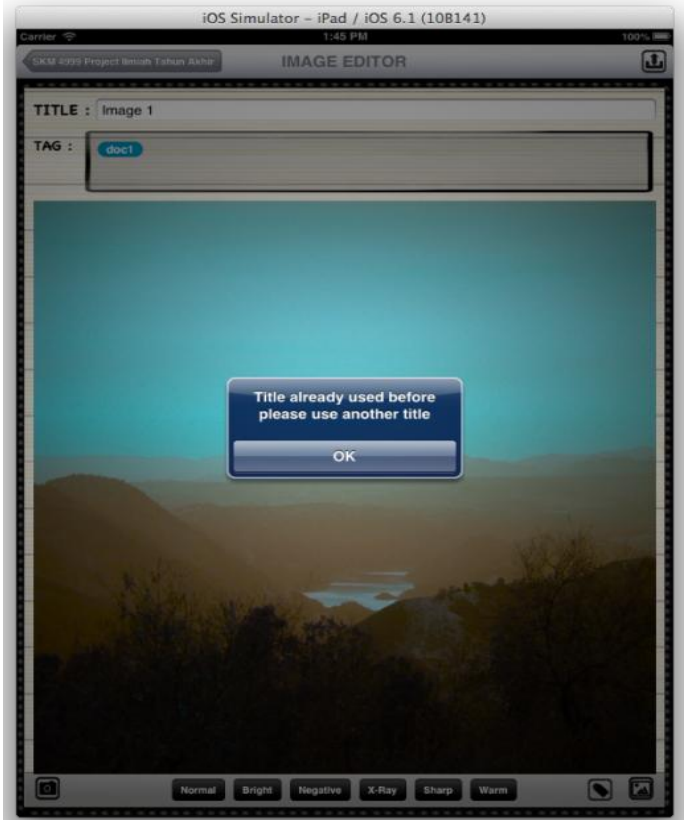

Fig. 5. 'Same title' alert in image editor.

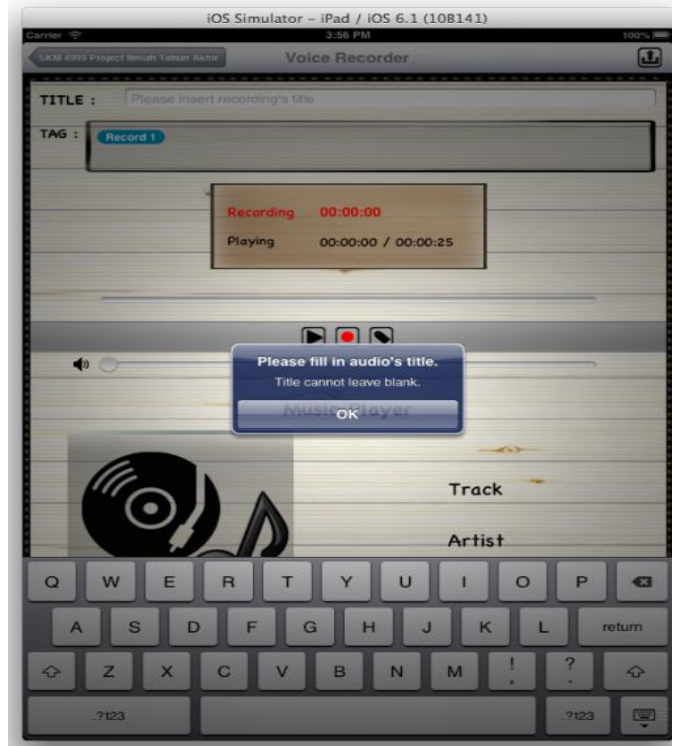

Fig. 6. A prompt for the user to input title for the audio file in audio editor.

\section{RESUlTS AND DisCUSSION}

In order to evaluate the effectiveness of the m-LMS, the prototype system has undergone two testing phases, which are alpha testing and beta testing. Alpha testing is performed by the software developers during the implementation phase to eliminate application errors and bugs as well as to ensure that the prototype system meet its requirements. Beta testing or also known as the acceptance testing, is performed by a group of selected users after project integration is completed and ready for release. For the beta testing, ten undergraduate students from the Faculty of Computer Science and Information Technology and Faculty of Modern Languages and Communication, Universiti Putra Malaysia are randomly selected based on voluntary to participate in the m-LMS user acceptance survey. All of the participants are required to explore the m-LMS on an iPad and they were also needed to complete a survey. The result of the survey is as shown in Fig. 8.

The survey shows that on average, $18 \%$ of the users are 
very satisfied while $58 \%$ are satisfied with the m-LMS user interface, functionalities, and system flow. They also agreed that the application is user friendly and informative. Only $24 \%$ are neutral about the system for all measured criteria. None of the users are unsatisfied or very unsatisfied with the proposed system. Besides that, $100 \%$ of the users believe that the m-LMS can help to improve the teaching and learning performance. This is because m-LMS allows the students to access their course materials at anywhere and anytime. As conclusion, on average, the users are satisfied with the m-LMS and believe that the system can help to improve the teaching and learning performance.

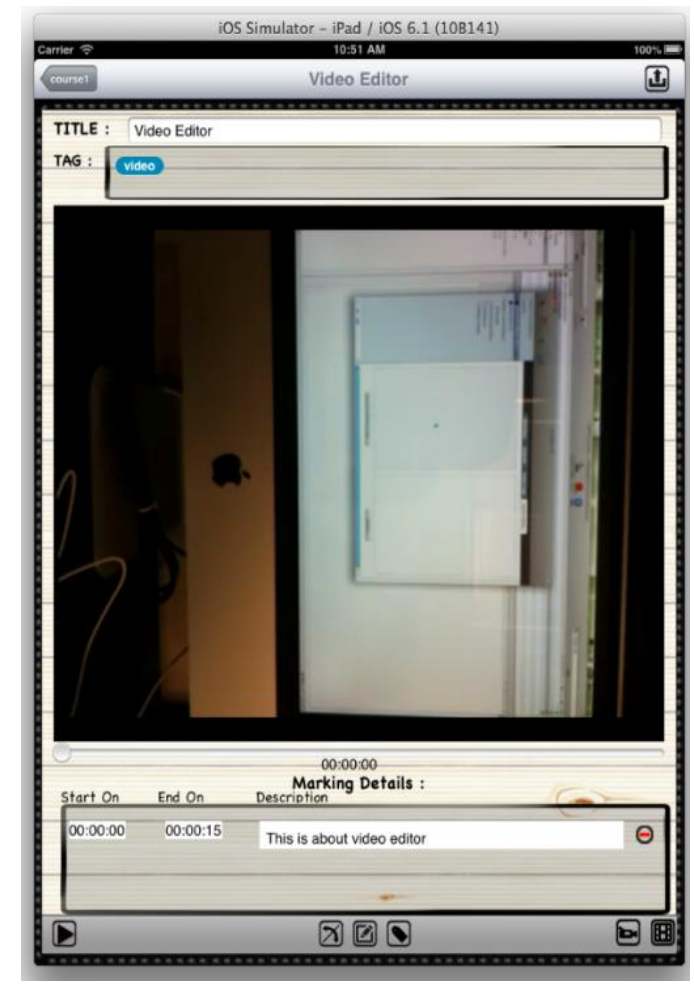

Fig. 7. Marking a particular video segment and writing description in the video editor.

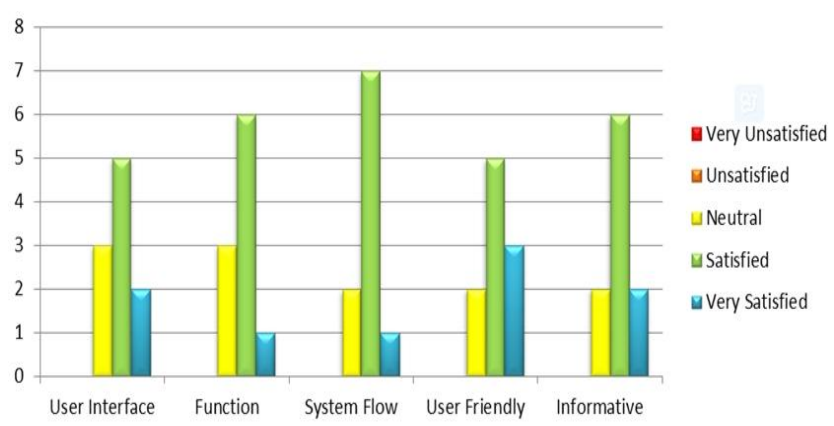

Fig. 8. Histogram of m-LMS user acceptance survey

\section{CONCLUSION AND FutURE RESEARCH}

This paper focused on facilitating students' learning through the development of an effective learning management system specifically for iPad. Based on the conducted survey, the m-LMS is able to provide the flexibility of course materials management, improve learning performance through the ability to access and analyze various multimedia documents at anytime and anywhere, and be an effective and user friendly system.
With the availability of the m-LMS, it is hoped that better learning environment can be provided for the students, which can lead the students to a deeper level of learning engagement, allowing the students to understand the content better, and even an improvement of the students' cognitive and psychomotor skills. Future enhancements of the m-LMS include enhancing user interface design, adding more advanced functions for each editor, and linking the m-LMS with social network.

\section{ACKNOWLEDGMENT}

The authors would like to thank Yow Hui Chin, Fion Wan Yie Tze, Teo Sin Hui, and Teh Xiang Wei for their technical contributions to this work and all participants in this study.

\section{REFERENCES}

[1] R. C. Clark and R. E. Mayer, E-learning and the Science of Instruction: Proven Guidelines for Consumers and Designers of Multimedia Learning, Wiley, 2011

[2] E. T. Welsh, C. R. Wanberg, K. G. Brown, and M. J. Simmering, "E-learning: Emerging uses, empirical results, and future directions," International Journal of Training and Development, vol. 7, no. 4, pp. 245-258, 2003

[3] M. J. Rosenberg, E-learning: Strategies for Delivering Knowledge in the Digital Age, New York: McGraw-Hill, vol. 9, 2001.

[4] J. G. Ruiz, M. J. Mintzer, and R. M. Leipzig, "The impact of e-learning in medical education," Academic Medicine, vol. 81, no. 3, pp. 207-212 2006.

[5] N. Nordin, M. A. Embi, and M. M. Yunus, "Mobile learning framework for lifelong learning," Procedia-Social and Behavioral Sciences, vol. 7, pp. 130-138, 2010.

[6] E. Al-Masri and Q. H. Mahmoud, "IClass: Improving the mobile learning experience," in Proc. International Conference on Computing and Information Technology (ICCIT), Al-Madinah, Saudi Arabia, 2012, pp. 587-592.

[7] T. Georgiev, E. Georgieva, and A. Smrikarov, "M-learning- a new stage of e-learning," in Proc. International Conference on Computer Systems and Technologies-CompSysTech, pp. 1-5, 2004.

[8] A. T. Korucu and A. Alkan, "Differences between m-learning (mobile learning) and e-learning, basic terminology and usage of m-learning in education," Procedia-Social and Behavioral Sciences, vol. 15, pp. 1925-1930, 2011.

[9] S. Henderson and J. Yeow, "iPad in education: A case study of ipad adoption and use in a primary school," in Proc. 45th Hawaii International Conference on System Science (HICSS), IEEE, 2012, pp. 78-87.

[10] T. J. McGill and J. E. Klobas, "A task-technology fit view of learning management system impact," Computers \& Education, vol. 52, no. 2 , pp. 496-508, 2009.

[11] S. Lonn, S. D. Teasley, and A. E. Krumm, "Who needs to do what where? Using learning management systems on residential vs. commuter campuses," Computers \& Education, vol. 56, no. 3, pp. 642-649, 2011

[12] Universiti Putra Malaysia, Putra Learning Management System. (2014). [Online]. Available: http://www.lms.upm.edu.my/i3learn/www/about.htm

[13] Universiti Teknologi Malaysia, E-Learning@UTM. (2014). [Online]. Available: http://elearning.utm.my/13142/

[14] Tunku Abdul Rahman University College, College E-Learning System (CEL). (2014). [Online]. Available: http://elearning4.tarc.edu.my/index.htm

[15] F. J. García-Peñalvo, M. A. Conde, M. Alier, and M. J. Casany, "Opening learning management systems to personal learning environments," Journal of Universal Computer Science, vol. 17, no. 9 , pp. 1222-1240, 2011.

[16] J. Brown, Exploring mobile learning: Part one of the mlearning series. (2009). [Online]. Available: http://na. blackberry. com.

[17] R. C. Meurant, "IPad tablet computing to foster korean EFL digital literacy," International Journal of u-and e-Service, Science and Technology, vol. 3, no. 4, pp. 49-62, 2010.

[18] D. Sethi, A. Tyagi, and K. Hans, "Apple iPhone operating system," International Journal of Computer Science and Management Research, vol. 2, no. 2, pp. 1473-1476, February 2013. 


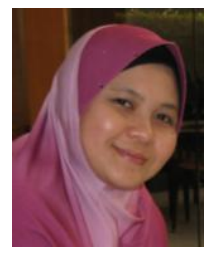

Mas Rina Mustaffa received her BCompSc degree in multimedia and MSc degree in multimedia systems in 2003 and 2006 respectively. She received her $\mathrm{PhD}$ for studies in content-based image retrieval (CBIR) in 2012. All of the three degrees are from Universiti Putra Malaysia (UPM), Serdang, Selangor, Malaysia. Her primary research interests are multimedia systems and applications, Content-Based Image Retrieval (CBIR), image processing, pattern recognition, and interactive multimedia.

She is currently a senior lecturer at the Department of Multimedia, Faculty of Computer Science and Information Technology, UPM. She has authored several publications in various journals and proceedings and presented at many conferences. She also has been actively involved in several international conferences as technical program committee.

Dr. Mas Rina is a member of the IACSIT, IEEE, and PECAMP.

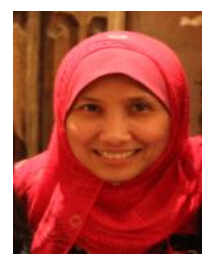

Evi Indriasari Mansor obtained her BSc. in IT from the Universiti Teknologi Petronas (UTP), Perak, Malaysia and MSc. degree in multimedia application \& virtual environments from the University of Sussex, UK. She was awarded a Ph.D. from the University of Manchester, UK for studies in multi-touch interactive tabletop for preschool children's play. Her work is interdisciplinary, combining research area from human computer interaction (HCI), early childhood development, education and innovation \& multimodal interactive technologies.

She is currently a senior lecturer at the Department of Multimedia, Faculty of Computer Science and Information Technology, Universiti Putra Malaysia (UPM).Her international experiences include worked as a user experience consultant for CBeebies (BBC London) on Innovation Project specialized in an interactive tabletops surface for children and as a co-researcher with IBM Research - Bangalore, India on mobiTop project. 